\title{
RESIDENCIAL ATALAIA - HABITAÇÃO SOCIAL EM PRESIDENTE PRUDENTE
}

\author{
Sibila Corral de Area Leao Honda ${ }^{1}$, Mayara Pissutti Albano²
}

${ }^{1}$ Docente dos cursos de Arquitetura e Urbanismo, Tecnologia em Design de Interiores, e Tecnologia em Design de Produto da Universidade do Oeste Paulista - UNOESTE. ${ }^{2}$ Mestranda em Meio Ambiente e Desenvolvimento Regional na Universidade do Oeste Paulista - UNOESTE. E-mail: sibila@unoeste.br

\section{RESUMO}

Este artigo visa à discussão sobre a habitação social em cidades médias brasileiras, refletindo sobre as características de sua implantação na estrutura urbana, bem como de seus moradores. Tem-se como estudo de caso a cidade de Presidente Prudente, no interior do Estado de São Paulo, por meio de um dos empreendimentos executados com financiamento do Programa de Arrendamento Residencial (PAR), do Governo Federal, o Conjunto Residencial Atalaia. Análise pós-ocupacional apoia a pesquisa, cuja metodologia está baseada em levantamento in loco. Evidencia-se o descaso sobre as diretrizes específicas do programa; assim como não se apresentam direcionamentos de expansão e adensamento urbanos. Reproduzem-se os processos de implantação da habitação social.

Palavras chave: Habitação de interesse social, Programa de Arrendamento Residencial, Avaliação pósocupacional.

\section{ATALAIA RESIDENCIAL - SOCIAL HOUSING IN PRESIDENTE PRUDENTE}

\begin{abstract}
This article seeks to discuss the social housing in medium-sized cities in Brazil, thinking on its implementation characteristics in urban structure and its residents. The study case is the city of Presidente Prudente, in São Paulo, state, taking one of the projects implemented with funding coming from the Federal program "Programa de Arrendamento Residencial (PAR)", the Residential Atalaia. The post-occupational survey.supports the analysis whose methodology was on-site survey. It is evident the neglect on the specific guidelines of the program, also fails to show directions of expansion and urban concentration. It reproduces the processes of implementation of social housing.

Keywords: Social Housing, Residential Leasing Program, Evaluation post-occupational.
\end{abstract}




\section{INTRODUÇÃO}

Este artigo tem como finalidade a discussão sobre habitação de interesse social executada por meio do Programa de Arrendamento Residencial - PAR, da Caixa Econômica Federal, e tem como estudo de caso o Conjunto Residencial Atalaia, implantado em Presidente Prudente, cidade de porte médio do interior do Estado de São Paulo.

Para Lorenzetti (2001, p. 04) a questão da moradia deve ser encarada como direito básico, integrando o "direito à subsistência, o qual, por sua vez, representa a expressão mínima do direito à vida". Os processos de urbanização no Brasil, refletindo no processo de elitização da distribuição de terras e na omissão de políticas públicas, geraram problemas de acesso à moradia, carência de infraestrutura de saneamento básico e de transporte, e redução da qualidade de vida nos centros urbanos.

Historicamente, no Brasil, a política habitacional federal tem concentrado parte dos esforços em programas voltados à habitação social. No governo de Getúlio Vargas, em 1938, foram instituídas as Carteiras Prediais dos Institutos de Aposentadoria e Previdência (IAPs). Em 1946, foi criada a Fundação da Casa Popular, durante o governo de Eurico Gaspar Dutra. No início da década de 1960, no governo de Jânio Quadros, o Instituto Brasileiro de Habitação (IBH) foi implantado, objetivando o acesso à habitação social e a extinção das favelas (HONDA, 2011).

No ano de 1964, com o Governo Militar, foram criados o Sistema Financeiro de Habitação (SFH), o Serviço Federal de Habitação e Urbanismo (SERFHAU) e o Banco Nacional de Habitação (BNH). Este representou uma inovação na política habitacional por se tratar de um banco, por corrigir a inflação nos financiamentos e propiciar a interação entre os setores público e privado, sendo este 0 executor das obras (KOWARICK; BONDUKI, 1994).

$\mathrm{O}$ BNH entre os anos de 1964 e 1986 financiou uma grande quantidade de habitações voltadas à população de baixa renda por meio de recursos do Fundo de Garantia e Tempo de Serviço (FGTS). Na sua maioria, os conjuntos habitacionais foram implantados nas áreas periféricas das cidades - franjas urbanas ou fora da malha consolidada, onde se encontra com maior facilidade áreas extensas com o custo do solo menor, que permitiu a construção em grande escala, barateando o custo da produção e adequando à possibilidade de pagamento do público alvo (BONATES, 2008).

Esse tipo de implantação contribuiu para a valorização das áreas circunvizinhas a esses conjuntos. Em suma, a produção do $\mathrm{BNH}$ ocasionou uma transformação "na estrutura e na paisagem urbana da maioria das cidades brasileiras", que, juntamente com o modelo da autoconstrução, contribuíram para a "expansão periférica das cidades brasileiras" (BONATES, 2008, p.148).

Após a extinção do BNH em 1986, numa conjuntura de crise econômica, instala-se no país um período sem políticas claras voltadas à habitação, ocasionando um aumento da necessidade de habitações, repercutida no aumento da quantidade de favelas e outras formas de moradias informais. Além destes fatores, a volubilidade das políticas setoriais que eram alteradas a cada mandato, criando e extinguindo programas habitacionais, também contribuíram para a crise no setor (HONDA, 2011)

A partir de 1995, na Presidência de Fernando Henrique Cardoso, impulsionada pela Conferência HABITAT II da ONU, em 1996, que propunha a promoção social e ambiental por meio do "desenvolvimento sustentável dos 
assentamentos humanos e a aquisição de abrigo adequado para todos" (ANTONUCCI, 2009, p.04), a questão habitacional tornou-se foco novamente, resultando em uma Política Nacional de Habitação (PNH) voltada ao atendimento das diversas necessidades habitacionais.

Nesse contexto, em 1999, foi criado o Programa de Arrendamento Residencial (PAR), por meio da Medida Provisória n.1.823/1999 e ratificado pela aprovação da Lei Federal $\mathrm{n}^{\circ} .10 .188 / 2001$, cujas características buscavam modificar as conseqüências causadas pelos planos e programas de promoção de habitação social anteriores (LIMA, 2007; CAIXA ECONÔMICA FEDERAL, 2008).

A pesquisa que embasa este artigo buscou compreender a habitação social e sua inserção em Presidente Prudente-SP, chegando até a execução de empreendimentos financiados pelo Programa de Arrendamento Residencial (PAR), tendo como estudo de caso o Conjunto Residencial Atalaia.

\section{O PAR EM PRESIDENTE PRUDENTE}

O Programa de Arrendamento Residencial (PAR) foi criado pelo Governo Federal em 1999. A Política Nacional de Habitação $(\mathrm{PNH})$, em vigor à época, apresentava como aspectos básicos o foco ao atendimento das camadas populacionais de baixa renda e a busca pelo aumento do controle social na gestão dos programas federais de habitação. Essa política estava apoiada na descentralização da execução de programas de habitação, saneamento e infraestrutura, atentando às diferenças regionais da sociedade e suas demandas.

Nessa perspectiva, o PAR visava ao financiamento habitacional para população com renda de até seis (6) salários mínimos; cuja principal diferença desse programa aos demais consistia na não aquisição direta do imóvel, por meio da figura do arrendamento, no qual o arrendatário tem a opção de compra após transcorrido tempo determinado de residência no imóvel.

Esse programa foi instituído por meio da Medida Provisória n.1.823/1999, e, em 2001, aprovado por meio da Lei $n^{\circ} .10 .188$, sem alterações. Poderia apresentar diversas modalidades de empreendimentos, mas visava exclusivamente a executar unidades residenciais em municípios com população urbana com mais de 100 mil habitantes (HONDA, 2011).

Os projetos dos empreendimentos poderiam ser horizontais ou verticais; adquiridos na planta, em construção, concluídos ou para reforma; em forma de condomínio ou loteamento; mas a prioridade deveria ser dada para implantação em locais inseridos na malha urbana, na tentativa de ocupação de vazios urbanos, em áreas com urbanização consolidada, com obrigatoriedade de infraestrutura mínima (vias de acesso, abastecimento de água potável, esgotamento sanitário, coleta de lixo sólido, rede de energia elétrica, transporte urbano público).

São vários os agentes participantes do Programa de Arrendamento Residencial: a Caixa Econômica Federal como executor (operacionalização), o Governo Federal como gestor, além de outros entes públicos e privados. O envolvimento dos Poderes Públicos municipais seria necessário, objetivando facilitar a implementação dos projetos, indicando áreas priorizadas para sua implantação, como as zonas especiais de interesse social (ZEIS), e fornecendo informações sobre demanda (CAIXA ECONÔMICA FEDERAL, 2008).

Novos empreendimentos seriam condicionados pela identificação de interessados na contratação de arrendamento pelo Poder Público local, cuja seleção ocorreria a critério da CAIXA, com antecedência de 180 dias da 
previsão de término da obra, para ocupação imediata após sua conclusão.

A normatização do PAR, por meio da CAIXA, apresentava padrão mínimo de acabamento das unidades, com habitações de 2 dormitórios e área útil mínima de $37 \mathrm{~m}^{2}$. Verificavam-se dois valores de aquisição à moradia do PAR - "especificação padrão" e "especificação mínima", cuja diferenciação baseava-se no público destinatário como arrendatário, sendo que, originalmente, o primeiro era para renda de até seis (6) salários mínimos, ou oito (8), se militares, policiais ou profissionais da segurança pública, conhecido como PAR 1; e o segundo para renda de até quatro (4) salários mínimos, PAR 2.

Independente da tipologia arquitetônica ou do padrão e valor do imóvel, era determinado que a quantidade de unidades por empreendimentos não deveria ultrapassar 160, com o número máximo de 500 unidades em um raio de $2 \mathrm{~km}$. Os limites deviam-se a incentivar conjuntos dentro da malha urbana, principalmente na ocupação de vazios urbanos, e facilitar a administração dos conjuntos.

A partir de 2003, com a mudança de Governo Federal e a criação do Ministério das Cidades (MCidades), a gestão do PAR passou a esse Ministério, ocorrendo alterações no programa, como o valor máximo da unidade habitacional e o prazo de opção de compra, que passou de 15 anos para aquisição a partir do $60^{\circ}$. mês de arrendamento. Outra alteração significativa foi a tendência dos locais de implantação dos empreendimentos na franja urbana, retornando a possibilidade de incremento no processo segregador urbano.

Entre os anos de 2003 e 2006, no município de Presidente Prudente, cinco (5) empreendimentos foram aprovados e construídos nos moldes do PAR, com características distintas, para os dois patamares de renda estipulados pelo programa: PAR 1 e PAR 2. A busca pelo programa nessa cidade foi iniciada por agentes privados (construtoras, imobiliárias e proprietários de terras), interessados em investir no mercado de habitação social.

A distribuição espacial na malha urbana está baseada na disponibilidade de áreas privadas, sem relação com déficit habitacional setorizado, disponibilidade de serviços e/ou equipamentos urbanos, ou outro levantamento elaborado. A Prefeitura Municipal de Presidente Prudente, nos processos do PAR, participou apenas com aprovação dos projetos junto à Secretaria de Planejamento, e colaborou com parte dos cadastramentos de interessados (HONDA, 2011).

A construtora Embras, de Marília-SP, assumiu o primeiro projeto com financiamento do PAR em Presidente Prudente: Conjunto Residencial Bela Vista, em novembro de 2003. Foram mais quatro empreendimentos construídos, a partir de então, Conjunto Residencial Atalaia (dez. 2003), Conjunto Residencial Laura (dez. 2003), Conjunto Residencial Esmeralda (set. 2004) e Conjunto Residencial Monte Carlo (out. 2006). Entre as construtoras envolvidas, apenas o Monte Carlo foi executado por empresa da cidade (Constrinvest).

Em março de 2009, o Governo Federal lançou o Programa Minha Casa Minha Vida (PMCMV), buscando incentivar a produção e a aquisição de unidades habitacionais voltadas a famílias com renda de até dez salários mínimos. Isso fez com que o PAR fosse deixado em segundo plano.

\section{CONJUNTO RESIDENCIAL ATALAIA E AVALIAÇÃO PÓS-OCUPACIONAL}

O Conjunto Residencial Atalaia foi executado na região norte da malha urbana de Presidente Prudente - SP (figura 1), sendo o único dos cinco empreendimentos financiados 
pelo PAR nessa cidade que não foi implantado na franja do malha da cidade (figura 2); assim sendo, é o único que ocupou um vazio urbano existente. No entanto, foi construído como condomínio fechado, tornando-se uma barreira urbana.

Esse conjunto contém onze edifícios multifamiliares de quatro pavimentos, e cada pavimento com quatro apartamentos, totalizando
176 unidades habitacionais. O condomínio possui estrutura linear de assentamento e área de lazer comum aos moradores (figura 3). Cada unidade habitacional possui dois dormitórios, sala de estar integrada com a sala de jantar, banheiro, e cozinha com lavanderia anexa, num total de $42 m^{2}$.

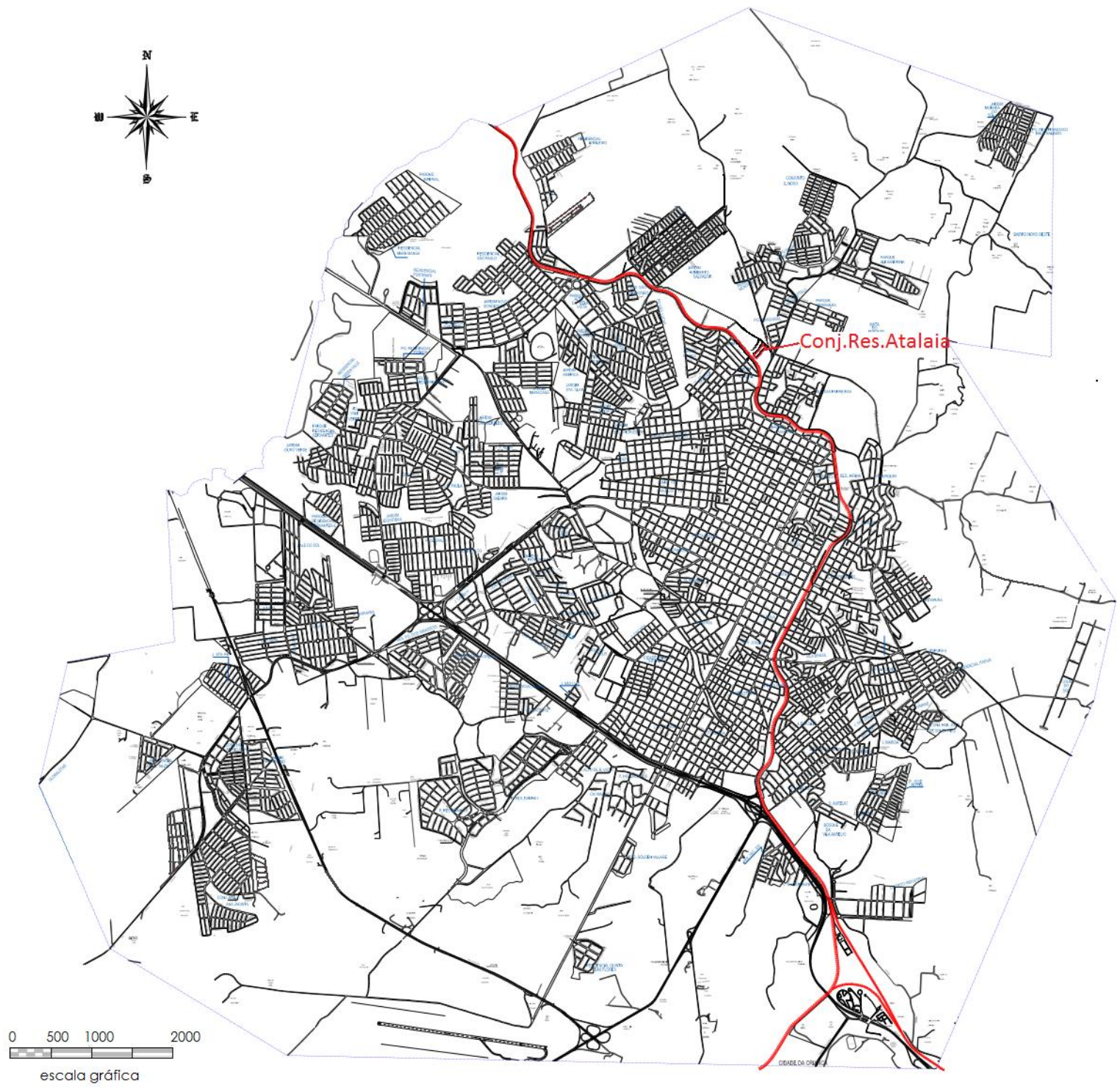

Figura 1. Localização do Conjunto Residencial Atalaia

Fonte: Secretaria de Planejamento - PMPP.

Desenho elaborado por Mayara Albano, 2009. 


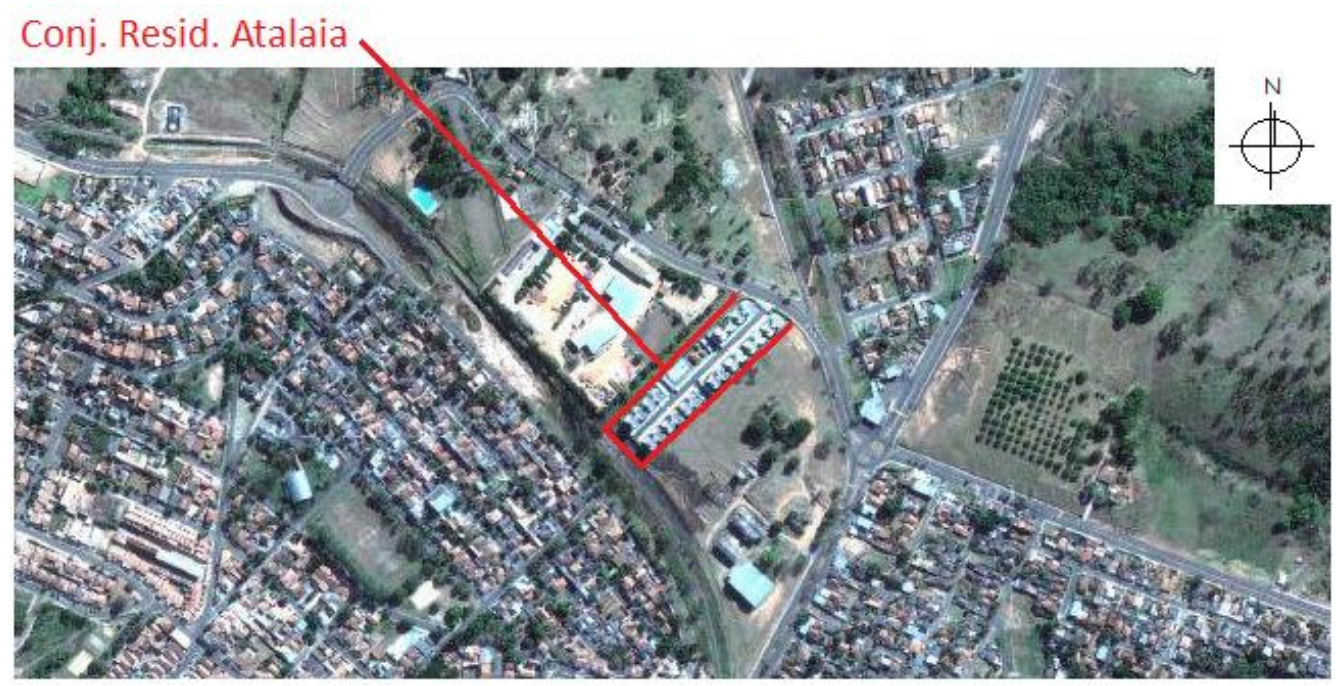

Figura 2. Imagem do Conjunto Residencial Atalaia e seu entorno próximo

Fonte: Google Maps, acesso em 15 nov 2010
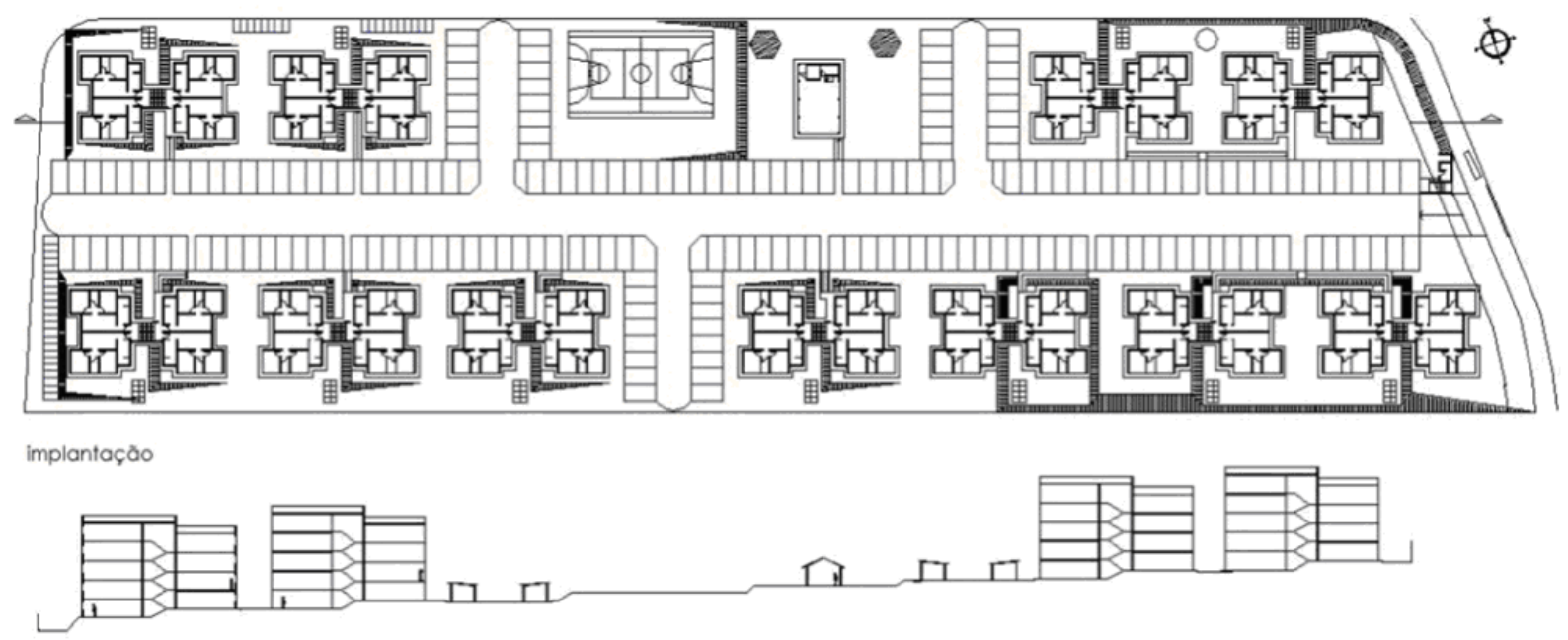

corte esquemático

Figura 3. Implantação do Conjunto Residencial Atalaia

Fonte: Processo de aprovação do projeto - Secretaria de Planejamento - PMPP.

Desenho elaborado por Mayara Albano, 2009.

O patamar de financiamento desse empreendimento é o PAR 1, com financiamento de unidades para renda familiar de até seis salários, ou seja, com renda de até $R \$ 1.440,00$ na data de entrega das unidades.

O conjunto residencial foi aprovado junto à Secretaria de Planejamento, Desenvolvimento Urbano e Habitação da Prefeitura Municipal de Presidente Prudente em dezembro de 2003, e implantado em 2004; totalizando oito anos no momento desta pesquisa, realizada em 2009.
A fim de obter dados reais das condições que se encontra o condomínio e seus moradores foram realizadas entrevistas com 32 moradores, ou seja, moradores adultos de $18 \%$ das unidades, escolhidos aleatoriamente, e indagados por meio de questões objetivas. A amostra de entrevistados foi composta de $43 \%$ de homens e $57 \%$ de mulheres, entre 21 e 56 anos.

Entre os moradores entrevistados, como pode ser verificado no gráfico $1,60 \%$ afirmaram residir no empreendimento desde a entrega das unidades, ou seja, arrendatários selecionados 
pela Caixa Econômica Federal; enquanto 40\% informaram que residem no conjunto habitacional há cinco anos ou menos, caracterizando um desacordo com a proposta do programa que seria a permanência do morador durante o período de arrendamento, evitando a evasão, compra ilegal da chave, entre outros problemas.

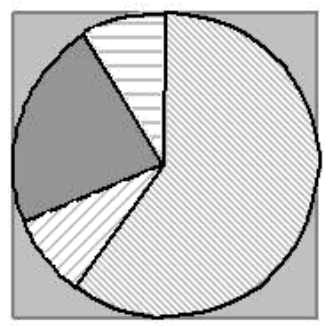

Na maioria das unidades residem famílias com duas pessoas ou mais, e, durante o período da pesquisa, pode-se constatar a grande presença de jovens casais sem filhos ou com filhos pequenos.
Gráfico 1. Tempo de residência no condomínio.

\begin{abstract}
O nível de escolaridade dos moradores entrevistados demonstra alto percentual de população com formação superior e pequeno percentual de população com baixa escolaridade (gráfico 2), diferindo das médias nacional e estadual para população de baixa renda, foco da habitação social.
\end{abstract}

\section{desde a entrega das unidades $(60 \%)$}

cinco anos $(9 \%)$

dois anos $(22 \%)$

menos de um ano $(9 \%)$
No entanto, o nível de escolaridade está equivalente com o percentual de chefes de família com emprego fixo e com registro em carteira (78\%), sendo que $87 \%$ dos moradores entrevistados afirmaram que a família é chefiada por um homem, e em apenas $8 \%$ das famílias a renda é composta por uma única pessoa.

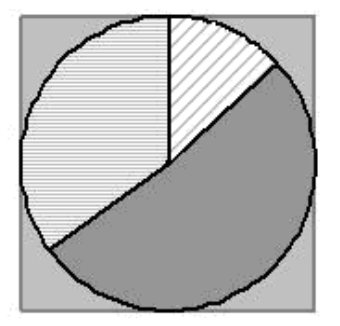

\section{escolaridade até ensino fundamental (13\%) escolaridade até ensino médio (52\%) $\square$ escolaridade - superior completo (35\%)}

Gráfico 2. Escolaridade dos entrevistados.

Uma das exigências do PAR, programa de financiamento do Conjunto Residencial Atalaia, empreendimento analisado, é a renda familiar, de até seis salários mínimos. Pode-se constatar que apenas $23 \%$ das famílias se enquadram na faixa de renda exigida, conforme pode ser verificado no gráfico 3 . Esse fato demonstra um descontrole do programa pela Caixa Econômica Federal, restringindo as oportunidades de moradia a famílias foco do programa.
Questões como segurança e localização do condomínio na estrutura da cidade também foram abordados na pesquisa. A sensação de segurança que os moradores têm em relação ao condomínio obteve avaliação positiva.

Sua localização também foi positiva, pois há vias rápidas de acesso e grande mobilidade urbana; sendo que a maioria dos residentes possui meios de locomoção próprios e não dependerem de transporte público. 


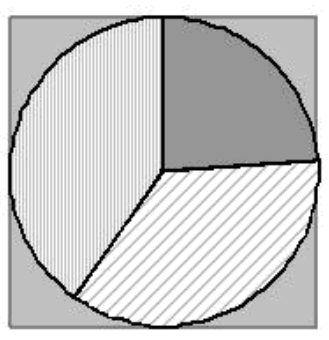

Gráfico 3. Renda familiar.

Esse levantamento possibilita verificar a realidade de um empreendimento de habitação de interesse social, associando às propostas e controle dos mesmos.

\subsection{Conjunto Residencial Atalaia e análise política}

A partir dessa pesquisa, foi possível constatar claramente como a política habitacional brasileira atua criando espaços urbanos e é desvirtuada quanto aos seus beneficiados.

O regulamento do PAR exigia, como uma das prioridades, a inserção dos empreendimentos na malha urbana consolidada, ocupando vazios urbanos. No caso desse conjunto analisado, isso ocorreu, embora tenha sido elaborado o projeto como barreira urbana por ser condomínio fechado. Mas importante notar que estimulou a ocupação populacional de região urbana com mobilidade, agregando positivamente à densidade populacional municipal.

Outro fato relevante é a renda dos beneficiados. Quando da entrega desse empreendimento de habitação de interesse social, muitas famílias que estariam incluídas nos parâmetros do programa não se tornaram beneficiadas, tendo sido preteridas em benefício de outras, com rendas bastante superiores. O descontrole se inicia na caracterização e renda familiares.

Também pode ser identificado que parte dos moradores não foram os beneficiados originais, morando no empreendimento há poucos anos. Ou seja, percebe-se que as famílias escolhidas alugaram ou venderam suas unidades, caracterizando uma situação ilegal quanto às normas do PAR, que visava à fixação dos beneficiados por prazo superior a quinze anos, por meio do arrendamento.

Assim, observa-se um descompasso entre as diretrizes do PAR e a realidade encontrada em um conjunto residencial financiado por meio desse programa federal de habitação social.

\section{CONSIDERAÇÕES FINAIS}

Considerando o Conjunto Residencial Atalaia, foco deste estudo, cujo financiamento partiu do Governo Federal, por meio do Programa de Arrendamento Residencial (PAR), verifica-se que as diretrizes definidas pelo próprio programa não são seguidas, assim como os objetivos iniciais da criação dessa modalidade de financiamento foram ignoradas.

Ou seja, não há beneficiados com renda inferior a três salários, assim como $76 \%$ dos moradores não se enquadram na faixa de renda estipulada pelo programa. Também se observou a falta de controle entre os arrendatários iniciais e os atuais moradores - contratos de gaveta ou locatários, ou seja, a não fixação das famílias selecionadas nos imóveis.

A relação do empreendimento com o espaço urbano dificulta questões de acessibilidade e mobilidade, pois, sendo um condomínio fechado de grandes dimensões, gera 
barreira urbana, que, juntamente com a ocupação das áreas contíguas, prejudica a circulação intraurbana. Esta questão não é sentida pelos moradores, conforme verificado na pesquisa, em função da posse de meio de transporte particular.

A partir desses aspectos levantados, conclui-se que, apesar da proposta do PAR, repetiram-se aspectos historicamente verificados nos conjuntos habitacionais tradicionais brasileiros.

\section{REFERÊNCIAS}

ANTONUCCI, D. ONU e $\mathbf{3 0}$ anos do Un-Habitat. São Paulo, 5ำ Fórum de Pesquisa FAU Mackenzie, 2009.

BONATES, M.F. O Programa de Arrendamento Residencial - PAR: acesso diferenciado à moradia e à cidade. Revista de Pesquisa em Arquitetura e Urbanismo, v.7, p. 1. p. 147 a 164. 2008. Disponível em: $<w w w$.arquitetura.eesc.usp.br/revista_risco/Risco 7-pdf/ 02_art10_risco7.pdf >. Acesso em: 8 nov. 2008.

CAIXA ECONÔMICA FEDERAL. Cartilha do PAR - Módulo Arrendamento. jun. 2008. Disponível em: <http://downloads.caixa.gov.br/_arquivos/ habita/par/CARTILHA_PAR_V16.pdf>. Acesso em: 07 out. 2010.

HONDA, S.C.A.L. Habitação de Baixa Renda como Produto do Capital - O Programa de Arrendamento Residencial (PAR) em Presidente Prudente-SP. 2011. Tese (Doutorado) - UPM, São Paulo.

KOWARICK, L.; BONDUKI, N. Espaço urbano e espaço político: do populismo à redemocratização. In: KOWARICK, L. (org.). As lutas sociais e a cidade: São Paulo - passado e presente. 2.ed. São Paulo: Paz e Terra, 1994. p.147-177.

LIMA, E.C.M. Políticas Federais de Habitação no Brasil (1930-2005): marcos históricos e institucionais. 2007. Dissertação (Mestrado) Universidade Federal de Alagoas, Maceió.

LORENZETTI, M.S.B. A questão habitacional no Brasil. Brasília: Consultoria Legislativa da Câmara dos Deputados. jun. 2001. (Relatório). Disponível em:

bd.camara.gov.br/bd/bitstream/handle/bdcamara/ 1469/questao__habitacional_lorenzetti.pdf. Acesso em: $1 \overline{7}$ ago. 2010.
ROMERO, M A.; VIANA, N.S. Procedimentos metodológicos para aplicação de avaliação pósocupação em conjuntos habitacionais para a população de baixa renda: do desenho urbano à unidade habitacional. In: ABIKO, A.K.; ORNSTEIN, S.W. (orgs.) Inserção Urbana e Avaliação Pós-Ocupação (APO) da Habitação de Interesse Social. São Paulo: FAUUSP, 2002. p. 210-242. 